\title{
Should kidney transplants during the COVID-19 pandemic be canceled or maintained?
}

\author{
Germano José Ferraz de Arruda ${ }^{1}$ \\ (iD)erônimo Ferraz de Arruda Neto ${ }^{2}$ \\ (iD Luís Cesar Fava Spessoto ${ }^{3}$ \\ Dosé Germano Ferraz de Arruda \\ (iD) Fernando Nestor Fácio $/ r^{3}$
}

\begin{abstract}
1. Mestrando do Curso de Ciências da Saúde, Faculdade de Medicina (FAMERP), São losé do Rio Preto, SP, Brasil. 2. Residente de Cirurgia Geral, Hospital São Domingos. Catanduva, SP, Brasil. 3. Professor de Urologia, Departamento de Urologia. Faculdade de Medicina (FAMERP/FUNFARME), São José do Rio Preto, SP, Brasil.
\end{abstract}

http://dx.doi.org/10.1590/1806-9282.66.7.864

KEYWORDS: Coronavirus Infections. Pandemics. Kidney Transplantation.

COVID-19 is the disease caused by the new coronavirus (SARS-CoV-2) and constitutes a pandemic that has not been previously recorded. There are currently more than 3.5 million cases confirmed in more than 200 countries and more than 100 thousand cases in Brasil. Thus, there has been a shift in the priorities of healthcare services, with material and human resources directed towards the treatment of the infected population'. This has been particularly detrimental to patients with chronic diseases.

Chronic kidney disease is closely related to arterial hypertension and diabetes, both risk factors for a worse prognosis of COVID-19. Special attention should be given to this population regarding the measures of individual protection and social isolation recommended by healthcare authorities. Kidney transplants require special care, as such patients are highly susceptible to this infection.

According to the American Society of Transplantation $^{2}$, transplants with a live donor are not recommended during the pandemic and epidemiological, clinical, and laboratorial investigations should be performed for deceased donors. Regarding the recipients, the risk-benefit ratio of the procedure should be weighed, as both patients and the surgical team currently run the risk of infection by the new coronavirus ${ }^{2}$. Moreover, infection by COVID-19 may not be diagnosed in donors and recipients due to the low sensitivity of the PCR analysis. An analysis of the bronchoalveolar lavage of the recipient can increase the accuracy of the test, but the time between the notification and execution of the transplantation may render this diagnostic test unfeasible ${ }^{3}$.

Challenges for transplant services and patients on dialysis during the pandemic include scarcity of financial resources, lack of beds and respirators, exhaustion of health professionals, and difficulty in performing social distancing due to visits to dialysis centers three times per week. Factors that were already problematic in developing countries are now worse with the imminent collapse of the healthcare system. Patients in need of a transplant are more susceptible to COVID-19 due to 
exposure to the hospital setting, the use of immunosuppressants, and the presence of chronic comorbidities.

There are not yet recommendations for an optimized approach regarding infected immunosuppressed patients. Kidney transplant patients affected by COVID-19 exhibit a broad clinical-laboratorial spectrum of the disease ${ }^{4}$. There is no evidence to consider kidney transplant a completely safe procedure in areas affected by the pandemic.

Brasil is a large country with different stages of the epidemiological curve of the disease. Thus, each case should be considered according to the characteristics of the recipient, geographic location of the transplant center, and incidence of infection by COVID-19 in order to minimize the risks for the patient and medical team. There are currently about 6000 kidney transplants performed annually and nearly 9000 patients on the waiting list ${ }^{5}$. Suspension of these surgeries will lead to an accumulation of patients on the waiting list for dialysis, as resources at dialysis centers are limited. Despite so many uncertainties, kidney transplants should be maintained as long as the healthcare system permits in order to avoid the loss of donated organs and an increase in morbidity and mortality rates of patients on the waiting list.

\section{Acknowledgments}

Funding sources - None.

\section{Disclosure}

The authors of this manuscript have no conflicts of interest to disclose.

\section{REFERENCES}

1. Sharma S, Lawrence C, Giovinazzo F. Transplant programs during COVID19: unintended consequences for health inequality. Am | Transplant. 2020. doi: 10.1111/ajt.15931.

2. American Society of Transplantation. COVID-19 (Coronavirus): FAQs for organ donation and transplantation. [cited 2020 May 23]. Mount Laurel: American Society of Transplantation; 2020. Available from: https://www. myast.org/sites/default/files/COVID19\%20FAQ\%20Tx\%20Centers\%20 2020.03.11_FINAL.pdf
3. Martino F, Plebani M, Ronco C. Kidney transplant programmes during the COVID-19 pandemic. Lancet Respir Med. 2020;8(5):e39.

4. Banerjee D, Popoola J, Shah S, Ster IC, Quan V, Phanish M. COVID-19 infection in kidney transplant recipients. Kidney Int. 2020;97(6):1076-82.

5. Associação Brasileira de Transplantes de Órgãos. Registro Brasileiro de Transplantes. São Paulo: Associação Brasileira de Transplantes de Órgãos; 2019. [cited 2020 May 23]. Available from: http://www.abto.org.br/abtov03/ Upload/file/RBT/2019/RBT-2019-jan-set-leitura.pdf 